\title{
Influência da massa molar de CMC no comportamento reológico e de filtração de suspensões argilosas
}

\section{(Influence of the molar mass of CMC in the rheological behavior and of filtration of clay suspensions)}

\author{
K. C. Nóbrega ${ }^{1}$, L. V. Amorim ${ }^{2}$ \\ ${ }^{I} P P G-C E M a t / U A E M a / U F C G,{ }^{2} P P G-C E M a t / U A E M / U F C G$ \\ R. Aprígio Veloso 882, Bairro Universitário, Campina Grande, PB 58429-900 \\ luciana@dem.ufcg.edu.br
}

\begin{abstract}
Resumo
A carboximetilcelulose (CMC) é um polímero linear aniônico usado como agente viscosificante e redutor de filtrado e em fluidos de perfuração. A estrutura química e massa molar do polímero interferem nas interações complexas entre as cadeias poliméricas e os sólidos minerais presentes na suspensão. Desta forma, este trabalho teve como objetivo avaliar o comportamento reológico e de filtração de suspensões argilosas em função do aumento da concentração de aditivo polimérico com diferentes massas molares. Para tanto, foi utilizada uma amostra de argila bentonítica, comercialmente conhecida por Volclay, duas amostras de carboximetilcelulose com diferentes massas molares (CMC $1\left(9,0 \times 10^{4} \mathrm{~g} / \mathrm{mol}\right)$ e CMC $\left.2\left(2,5 \times 10^{5} \mathrm{~g} / \mathrm{mol}\right)\right)$ e mesmo grau de substituição $(\mathrm{DS}=0,7)$, e uma amostra de calcita. Foram determinadas as propriedades reológicas (viscosidades aparente e plástica, limite de escoamento e força gel) e de filtração (volume de filtrado, spurt loss), espessura e permeabilidade do reboco, e poder de retenção) das suspensões argilosas. As propriedades reológicas e de filtração das suspensões argilosas preparadas com aditivos poliméricos são fortemente dependentes das interações CMC-argila e CMC-calcita e estas, por sua vez, são dependentes do grau de viscosidade e tamanho da cadeia do polímero.
\end{abstract}

Palavras-chave: carboximetilcelulose, argila bentonítica, calcita, interações, grau de viscosidade.

\begin{abstract}
The carboxymethylcellulose (CMC) is a linear anionic polymer used as viscosifier agent and filtrate reducer in drilling fluids. The chemical structure and molecular weight of the polymer interfere in the complex interactions between the polymeric chains and the mineral solids in the suspension. This study aimed to evaluate the rheological behavior and filtration process of clay suspensions in function of the increase of the polymeric additive concentration with different molar masses. For this, a sample of bentonite clay, two samples of CMC with different molecular weight (CMC $1\left(9.0 \times 10^{4} \mathrm{~g} / \mathrm{mol}\right)$ and CMC $\left.2\left(2.5 \times 10^{5} \mathrm{~g} / \mathrm{mol}\right)\right)$ and same degree of substitution (0.7) and one sample of calcite were used. The rheological properties (apparent viscosity, plastic viscosity, yield limit and gel strength, and filtration process parameters (filtrate volume, spurt loss, cake thickness and permeability, and retaining power of the clay suspensions were determined. The rheological and filtration properties of the clay suspensions prepared with polymeric additives are strongly dependent of the CMC-clay interactions and CMC-calcite and these are dependent on the viscosity grade and chain size of the polymer.
\end{abstract}

Keywords: carboxymethylcellulose, bentonite clay, calcite, interactions, viscosity grade.

\section{INTRODUÇÃO}

As atividades de perfuração são extremamente importantes para a exploração de petróleo, já que o poço caracteriza-se como meio de ligação entre o reservatório e a superfície. A minimização do tempo de perfuração e do dano à zona produtora tem estimulado o constante desenvolvimento em tecnologia de fluidos de perfuração [1]. Os fluidos de perfuração, também denominados lamas, são considerados como misturas complexas de sólidos, líquidos, produtos químicos e, por vezes, até gases, utilizados para auxiliar o processo de perfuração de poços de petróleo, poços tubulares e operações de sondagem, desempenhando uma série de funções [2]. Dispersões de sólidos em líquidos são em geral fluidos não newtonianos, principalmente quando os sólidos dispersos tendem a interagir (solvatar, inchar, etc.) com a fase líquida. Os fluidos de perfuração base água (suspensões de argila em água) são exemplos de fluidos não newtonianos, ou seja, a relação entre a tensão de cisalhamento e a taxa de deformação não é constante $[3,4]$. A escolha de um fluido para perfurar um determinado tipo de formação rochosa considera alguns significativos requisitos como custo, disponibilidade de água, pressão da formação, inclinação do poço e preservação do meio ambiente [5]. Por isto, tem-se procurado desenvolver fluidos aquosos com produtos que atendam as crescentes exigências técnicas, 
ambientais (baixa toxidade, biodegradabilidade e baixa bioacumulação) e econômicas. Dentre os fluidos aquosos, destacam-se os fluidos argilosos (suspensões argilosas). Esses geralmente são utilizados na perfuração de camadas rochosas superficiais, compostas na maioria das vezes de sedimentos inconsolidados, sendo empregada a argila bentonítica sódica em sua preparação devido sua elevada capacidade de hidratação [2]. O processo de filtração referese à fase líquida do fluido de perfuração sendo forçado contra uma formação permeável devido à ação de um diferencial de pressão. Durante esse processo, as partículas sólidas contidas no fluido são "filtradas", sendo retidas nas paredes da formação, formando, assim, o reboco (filter cake). Portanto, o fluido deve ser formulado de modo a selar as formações permeáveis o mais rápido possível com um fino e impermeável reboco [6]. A invasão de filtrado na rocha reservatório é conhecida por ser uma das principais causas da redução da produtividade do poço. A capacidade produtiva é prejudicada por interações complexas entre o fluido e a rocha que reduzem a permeabilidade do óleo e gás, causam danos à formação e contribuem para avaliações equivocadas sobre o perfil da formação rochosa [7].

Polieletrólitos têm sido frequentemente utilizados em fluidos de perfuração base água, principalmente, a goma xantana e a carboximetilcelulose. Esses polímeros são, provavelmente, os mais usados rotineiramente para aumentar a viscosidade e controlar a perda de filtrado para a formação, respectivamente [8,9].

A carboximetilcelulose, derivada da celulose, é um polímero natural insolúvel em água. Para tornar-se solúvel, é modificado para a forma de polieletrólito. Esta modificação envolve uma alteração da unidade de repetição do polímero pela introdução do grupo carboximetil aniônico $\left(\mathrm{CH}_{2} \mathrm{OCH}_{2} \mathrm{COO}^{-} \mathrm{Na}^{+}\right)$. Este polímero é então obtido por meio da reação entre a celulose, o hidróxido de sódio $(\mathrm{NaOH})$, formando a álcali-celulose, e o ácido monocloroacético $\left(\mathrm{ClCH}_{2} \mathrm{COOH}\right)$. Nesta reação tem-se a substituição dos hidrogênios das hidroxilas da celulose por grupos carboximetil $\left(-\mathrm{CH}_{2} \mathrm{COO}^{-} \mathrm{Na}^{+}\right)$. A substituição geralmente ocorre no grupo hidrometil $\left(-\mathrm{CH}_{2} \mathrm{OH}\right)$, formando o polieletrólito solúvel [10-12]. As propriedades físico-químicas e aplicações da CMC dependem, essencialmente, da viscosidade de suas soluções aquosas, do grau médio de substituição (DS), grau médio de polimerização (DP), uniformidade da substituição e pureza do produto [10-12]. O DS é definido como o número médio de grupos carboximetílicos substituídos por unidade monomérica; seu valor pode atingir um máximo de 3,0, mas na prática, são atingidos valores máximos entre 1,2 e 1,4. A solubilidade da CMC é função direta do DS; para DS maiores que 0,45 as CMCs são consideradas solúveis em água. As CMCs comerciais apresentam DS entre 0,7 e 0,8 ; quanto maior DS, maior a solubilidade da $\mathrm{CMC} \mathrm{e}$ a estabilidade da viscosidade a $\mathrm{pH}$ baixo e na presença de sal. DP é definido como o número médio de unidades monoméricas ao longo da cadeia polimérica; quanto maior DP, maior será o peso molecular e a viscosidade do polímero
$[10,13]$. A concentração e estrutura molecular do polímero, o grau total de substituição, a massa molar, a temperatura, o teor de sal, o pH e a presença de surfactantes tem um efeito considerável sobre as propriedades reológicas de soluções de CMC [14]. A ação viscosificante da CMC em fluidos argilosos deve-se à hidratação do polímero (grupo carboximetil- $\mathrm{CH}_{2} \mathrm{OCH}_{2} \mathrm{COONa}$ ) que quando em solução aquosa, libera o íon $\mathrm{Na}^{+}$tornando-se aniônico e livre pra hidratar-se. Desta forma, moléculas de água são adsorvidas nas cadeias do polímero, que adquirem uma configuração alongada e elevam a viscosidade do sistema [10]. A utilização da carboximetilcelulose em fluidos argilosos forma um filme de baixa permeabilidade nas paredes do poço, controlando a quantidade de filtrado que invade a rocha e a espessura do reboco. As partículas de argila adsorvem o polímero e ajudam a dar consistência ao reboco formado, tornando o mesmo menos permeável $[15,16]$. Na literatura encontram-se disponíveis muitos trabalhos sobre o uso da carboximetilcelulose em fluidos de perfuração aquosos e posterior avaliação das propriedades físicoquímicas do fluido após aditivação polimérica. No entanto, os efeitos das características moleculares da CMC sobre as propriedades reológicas e de filtração de fluidos argilosos ainda não foram totalmente explorados [17-21].

Os efeitos da massa molar e grau médio de substituição (DS) da CMC, bem como dos pH 10 e pH 12 do meio, sobre o comportamento reológico dos fluidos de perfuração e sobre a estrutura do fluido adsorvido foram investigados [18]. O meio alcalino favorece a geração de cargas negativas nos polissacarídeos e repulsão eletrostática intermolecular, aumentando seus volumes hidrodinâmicos. Os mecanismos de adsorção da CMC sobre a superfície do $\mathrm{CaCO}_{3}$ e da argila em fluidos de perfuração aquosos foram estudados [21]. Foram utilizadas no estudo três amostras de carboximetilcelulose com diferentes massas molares e graus de substituição e três amostras de calcita, com diferentes diâmetros médios de partículas e curvas de distribuição em tamanho. A análise conjunta dos resultados experimentais indicou que altas massas molares da CMC propiciam melhores resultados no controle das propriedades reológicas, de filtração e de inchamento de argilas; entretanto, efeito contrário é observado com o aumento do grau de substituição. Os polímeros utilizados nos fluidos de perfuração aquosos não agem apenas como viscosificantes, mas também apresentam um forte efeito sobre os sólidos presentes no fluido, no reboco e nos poros da formação, atuando em conjunto com os agentes de ponte a fim de selar de forma mais eficiente as paredes do poço, sendo este efeito função da sua estrutura e massa molar. Os efeitos dos polímeros nas características do reboco e no volume de filtrado podem ser justificados pela sua incorporação no reboco e, mais especificamente, pelas suas interações com os sólidos e solutos presentes no fluido.

Este trabalho teve como objetivo avaliar o comportamento reológico e de filtração de suspensões argilosas em função do aumento da concentração de aditivo polimérico com diferentes massas molares. 


\section{MATERIAIS E MÉTODOS}

Para a preparação das suspensões argilosas foram utilizados os seguintes aditivos: uma amostra de argila bentonítica naturalmente sódica proveniente dos Estados Unidos, conhecida por Volclay, fornecida pela Empresa Bentonit União Nordeste Ltda., Campina Grande, PB; duas amostras de carboximetilcelulose com diferentes massas molares e mesmo grau de substituição (CMC1, 9,0 x 10 $\mathrm{g} / \mathrm{mol}$ - DS 0,7) e (CMC2, 2,5 x $10^{5} \mathrm{~g} / \mathrm{mol}$ - DS 0,7), Sigma Aldrich Brasil, e uma amostra de calcita fornecida pela Empresa System Mud an Imdex Ltd. Co..

\section{Metodologia}

Formulação das suspensões argilosas: foram preparadas treze formulações de suspensões argilosas com concentração fixa (10 g) de argila bentonítica e diferentes concentrações de CMC ( 0 a 2 g) e calcita $(0$ a $10 \mathrm{~g})$. As formulações estão apresentadas na Tabela I.

Preparação das suspensões argilosas: os aditivos foram introduzidos de acordo com as concentrações apresentadas na Tabela I, a $350 \mathrm{~mL}$ de água deionizada, sob agitação constante a $13000 \mathrm{rpm}$ em agitador Hamilton Beach 936. Após a introdução, a velocidade do agitador foi aumentada para $17000 \mathrm{rpm}$, permanecendo por $20 \mathrm{~min}$.

Propriedades reológicas: para o estudo do comportamento reológico, após $24 \mathrm{~h}$ de repouso, a suspensão foi agitada durante 5 min em agitador mecânico Hamilton Beach 936 a $17000 \mathrm{rpm}$. Em seguida, a suspensão foi transferida para o recipiente do viscosímetro Fann 35A. O viscosímetro foi acionado a $600 \mathrm{rpm}$ durante $2 \mathrm{~min}$ e efetuou-se a leitura. Logo após, foi mudada para a velocidade de $300 \mathrm{rpm}$, com leitura após $15 \mathrm{~s}$. Novamente, foi mudada a velocidade para $200 \mathrm{rpm}$. Após a estabilização do sistema, realizou-se a leitura. O mesmo procedimento foi utilizado para as velocidades de 100, 6 e 3 rpm. Para obtenção da força gel inicial, a suspensão foi submetida a $600 \mathrm{rpm}$ durante $15 \mathrm{~s}$, em seguida a velocidade foi alterada para $3 \mathrm{rpm}$ e a suspensão ficou em repouso durante $10 \mathrm{~s}$, fez-se então a leitura obtendo o valor da força gel inicial. Em seguida, para a obtenção da força gel final, a suspensão foi deixada em repouso durante 10 min e efetuada a leitura $3 \mathrm{rpm}$. Com os dados das leituras obtidas no viscosímetro, calculou-se a viscosidade aparente (VA), a viscosidade plástica (VP), o limite de escoamento (LE) e a força gel (FG) segundo norma [22]. A viscosidade aparente é o valor obtido a $600 \mathrm{rpm}$ dividido por 2 , em cP, e a viscosidade plástica é a diferença das leituras obtidas a 600 rpm e a 300 rpm, também em cP. O limite de escoamento é a diferença entre a leitura obtida a $300 \mathrm{rpm}$ e a viscosidade plástica (VP), em N/m², e a força gel é a diferença das leituras obtidas para a força gel final e a força gel inicial, também $\mathrm{em} \mathrm{N} / \mathrm{m}^{2}$.

\section{Propriedades de filtração}

Volume de filtrado: o volume de filtrado foi determinado em filtros-prensa API Fann. A suspensão foi agitada por $1 \mathrm{~min}$, e em seguida foi transferida para o recipiente do filtro-prensa, com aplicação de uma pressão de 100 psi $\left(7,0 \mathrm{kgf} / \mathrm{cm}^{2}\right)$ durante $30 \mathrm{~min}$.

Filtrado inicial (spurt loss): o filtrado inicial (SPL) foi determinado conforme a norma ANSI/API 13I [23]. O filtrado foi coletado em filtros-prensa API Fann nos tempos de 1, $5,7,5,10,15,25$ e $30 \mathrm{~min}$. Através dos valores encontrados para o volume de filtrado, em diferentes tempos, foram plotados os gráficos (volume de filtrado acumulado em função

Tabela I - Formulações das suspensões argilosas.

[Table I - Formulations of clay suspensions.]

\begin{tabular}{ccccc}
\hline Suspensões & $\begin{array}{c}\text { Concentração de } \\
\text { Argila }\end{array}$ & $\begin{array}{c}\text { Concentração de } \\
\text { CMC 1 }\end{array}$ & $\begin{array}{c}\text { Concentração de } \\
\text { CMC 2 }\end{array}$ & $\begin{array}{c}\text { Concentração } \\
\text { de calcita }\end{array}$ \\
\hline 1 & 10,0 & - & - & - \\
2 & 10,0 & 1,0 & - & - \\
3 & 10,0 & 1,5 & - & - \\
4 & 10,0 & 2,0 & - & - \\
5 & 10,0 & 1,0 & - & 10,0 \\
6 & 10,0 & 1,5 & - & 10,0 \\
7 & 10,0 & 2,0 & - & 10,0 \\
8 & 10,0 & - & 1,0 & - \\
9 & 10,0 & - & 1,5 & - \\
10 & 10,0 & - & 2,0 & 10,0 \\
11 & 10,0 & - & 1,0 & 10,0 \\
12 & 10,0 & - & 1,5 & 10,0 \\
13 & 10,0 & - & 2,0 & \\
\hline
\end{tabular}

*Concentrações ( $g / 350 \mathrm{~mL}$ de água deionizada) 
da raiz quadrada do tempo) para determinar a perda de filtrado inicial. Assim, em VF x tempo ${ }^{1 / 2}$, o ponto onde a curva intercepta o eixo y, que indica que o tempo tende a zero, mostra o valor do spurt loss.

Espessura de reboco: para a determinação da espessura do reboco foi seguida a metodologia desenvolvida [15], que consiste nas seguintes etapas: foi coletado o papel de filtro com o reboco após a realização do ensaio para a determinação do volume de filtrado; em seguida, esse papel de filtro foi lavado três vezes a uma vazão de $\sim 110 \mathrm{~L} / \mathrm{h}$ com o auxílio de um recipiente de nível constante com vazão regulável, a uma distância de $\sim 7 \mathrm{~cm}$ do controlador de vazão com diâmetro $15 \mathrm{~mm}$ e com ângulo de ataque do fluxo da água de $45^{\circ}$. Após a lavagem para a retirada do excesso da suspensão na superfície do reboco, o papel de filtro foi colocado entre duas lâminas de vidro, sendo submetido a uma pressão de $\sim 277,6 \mathrm{~N} / \mathrm{m}^{2}$ por $2 \mathrm{~min}$ com a finalidade de uniformizar a superfície do reboco. Após, mediu-se a espessura do reboco com um extensômetro. Foram feitas cinco medidas das espessuras das lâminas de vidro e do papel de filtro com o reboco em pontos distintos. Foi então obtida a média aritmética das cinco determinações e descontada a espessura das duas placas de vidro e do papel molhado, sendo determinada a espessura do reboco em mm com aproximação em centésimos.

Permeabilidade do reboco: a permeabilidade do reboco foi determinada segundo norma [23], de acordo com a equação $1\left(\mathrm{k}=\mathrm{Q}_{\mathrm{f}} \varepsilon \cdot \mu .8,95 \times 10^{-5}\right)$, na qual $\mathrm{k}$ é em $\mathrm{mD}, \mathrm{Q}_{\mathrm{f}} e ́$ $o$ volume de filtrado $\mathrm{em}^{3}, \varepsilon$ é a espessura do reboco em $\mathrm{mm}, \mathrm{e} \mu$ a viscosidade da fase líquida da suspensão em $\mathrm{cP}$.

Poder de retenção: o poder de retenção foi obtido pela razão entre o volume da suspensão argilosa com o volume de filtrado, como mostra a equação $2\left(R=Q_{L} / Q_{f}\right)$, na qual $Q_{L}$ é o volume da fase dispersante na unidade de fluido em $\mathrm{mL}$, e $Q_{f}$ o volume da fase líquida cedida (filtrado) durante um tempo t, em $\mathrm{mL}$ [16].

\section{RESULTADOS E DISCUSSÃO}

\section{Avaliação das propriedades reológicas}

Nas Figs. 1 e 2 estão apresentadas as curvas de fluxo das suspensões argilosas preparadas de acordo com as formulações apresentadas na Tabela I.

Todas as suspensões argilosas formuladas, independente do tipo de carboximetilcelulose utilizada, apresentaram comportamento pseudoplástico com limite de escoamento. Este tipo de comportamento pode ser causado por diversos fatores, dentre os quais: as características físicas das partículas, como sua área superficial, formato e dimensões; o tipo de interação entre as partículas (atração ou repulsão); e a concentração, peso molecular e conformação de moléculas de dispersante presentes no meio líquido [24]. O comportamento pseudoplástico observado nas suspensões estudadas pode ser explicado pela mudança na conformação das cadeias dos polímeros com o aumento do gradiente de


Figura 1: Curvas de fluxo das suspensões preparadas apenas com argila (suspensão 1), com argila e CMC 1 (suspensões 2, 3 e 4) e, com argila, CMC 1 e calcita (suspensões 5, 6 e 7).

[Figure 1: Flow curves of the suspensions prepared only with clay (suspension 1), with clay and CMC 1 (suspensions 2, 3 and 4) and with clay, CMC 1 and calcite (suspensions 5, 6 and 7).]

velocidade. Estas cadeias tendem a se alinhar paralelamente à direção do fluxo, diminuindo a resistência ao escoamento [25]. Comparando a curva de fluxo da suspensão 1, que continha apenas $10 \mathrm{~g}$ de argila em sua composição, com as curvas das suspensões que continham em sua composição CMC1 (suspensões 2, 3 e 4) ou CMC2 (suspensões 8, 9 e 10), é possível visualizar o aumento da tensão de cisalhamento. Esse comportamento pode ser justificado pela presença da carboximetilcelulose com diferentes massas molares, a qual confere maior viscosidade às suspensões argilosas. De acordo com as curvas de fluxo verifica-se, ainda, que a tensão de cisalhamento aumenta com a concentração de polímero, independende da sua massa molar. Os parâmetros das curvas de fluxo das suspensões foram determinados através da equação da curva de fluxo, que representa a Lei da Potência. As equações das curvas, os coeficientes de determinação $\left(\mathrm{R}^{2}\right)$, os índices de comportamento de fluxo (n) e os índices de consistência do fluido (K) das suspensões argilosas estudadas estão apresentados na Tabela II.

$\mathrm{Na}$ literatura do escoamento de fluidos existe um variado número de equações matemáticas que podem ser utilizadas para descrever o comportamento de um fluido em particular. 

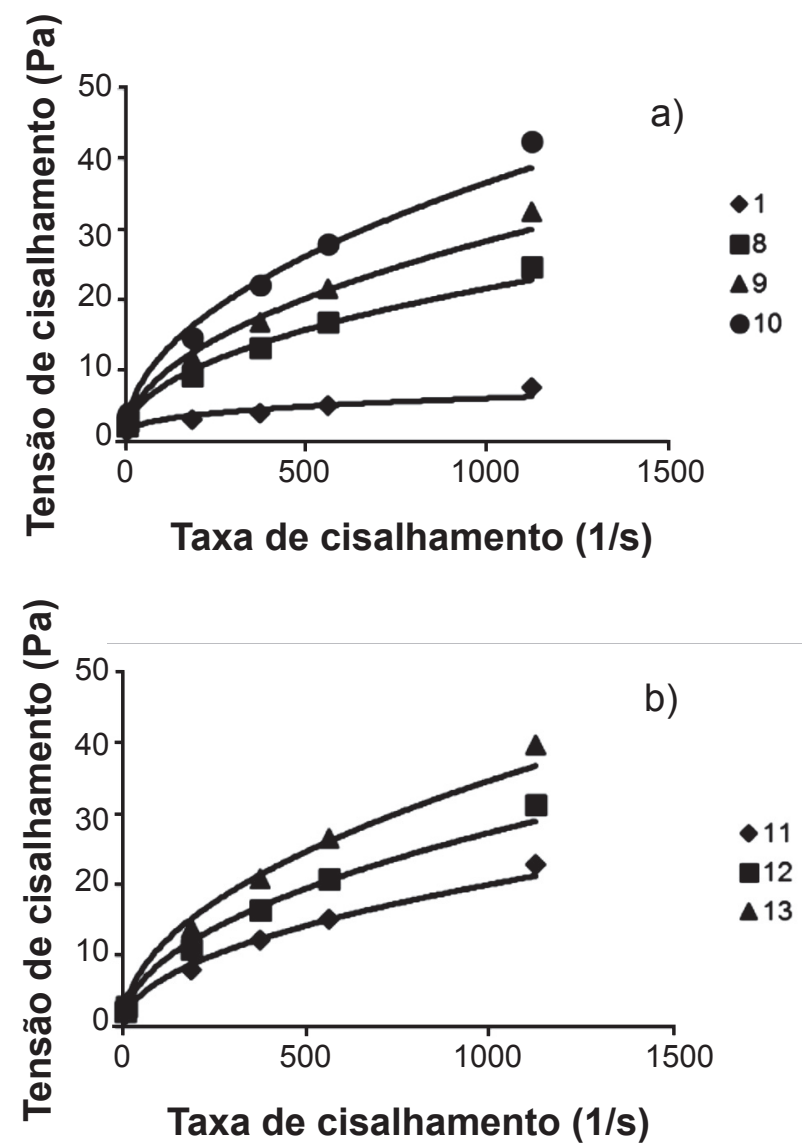

Figura 2: Curvas de fluxo das suspensões preparadas apenas com argila (suspensão 1), com argila e CMC 2 (suspensões 8, 9 e 10) e, com argila, CMC 2 e calcita (suspensões 11, 12 e 13).

[Figure 2: Flow curves of the suspensions prepared only with clay (suspension 1), with clay and CMC 2 (suspensions 8, 9 and 10) and with clay, CMC 2 and calcite (suspensions 11, 12 and 13).]

Tabela II - Equações e parâmetros das equações matemáticas das curvas de fluxo das suspensões argilosas.

[Table II - Equations and parameters of the mathematical equations of the flow curves of the clay suspensions.]

\begin{tabular}{ccccc}
\hline Suspensões & Equação & $\mathrm{R}^{2}$ & $\mathrm{n}$ & $\mathrm{K}$ \\
\hline 1 & $\mathrm{y}=0,7062 \mathrm{x}^{0,3101}$ & 0,9614 & 0,3101 & 0,7062 \\
2 & $\mathrm{y}=0,4574 \mathrm{x}^{0,4224}$ & 0,9892 & 0,4224 & 0,4574 \\
3 & $\mathrm{y}=0,3984 \mathrm{x}^{0,4994}$ & 0,9944 & 0,4994 & 0,3984 \\
4 & $\mathrm{y}=0,3444 \mathrm{x}^{0,5414}$ & 0,9948 & 0,5414 & 0,3444 \\
5 & $\mathrm{y}=0,4672 \mathrm{x}^{0,4426}$ & 0,9903 & 0,4426 & 0,4672 \\
6 & $\mathrm{y}=0,207 \mathrm{x}^{0,5877}$ & 0,9928 & 0,5877 & 0,207 \\
7 & $\mathrm{y}=0,3791 \mathrm{x}^{0,5208}$ & 0,9921 & 0,5208 & 0,3791 \\
8 & $\mathrm{y}=0,9068 \mathrm{x}^{0,4596}$ & 0,9967 & 0,4596 & 0,9068 \\
9 & $\mathrm{y}=0,9646 \mathrm{x}^{0,4898}$ & 0,9927 & 0,4898 & 0,9646 \\
10 & $\mathrm{y}=1,2894 \mathrm{x}^{0,4851}$ & 0,9933 & 0,4851 & 1,2894 \\
11 & $\mathrm{y}=0,689 \mathrm{x}^{0,4885}$ & 0,9939 & 0,4885 & 0,689 \\
12 & $\mathrm{y}=0,9518 \mathrm{x}^{0,4865}$ & 0,9966 & 0,4865 & 0,9518 \\
13 & $\mathrm{y}=1,189 \mathrm{x}^{0,4885}$ & 0,9944 & 0,4885 & 1,189 \\
\hline
\end{tabular}

Dentre esses modelos matemáticos, os mais aceitos para descrever o comportamento dos fluidos de perfuração base água utilizados na indústria do petróleo são: o modelo de Bingham ou plástico ideal, o modelo de Ostwald ou modelo de potência e o modelo de potência com limite de escoamento ou modelo de Hersclell-Bulkely [4, 10].

O coeficiente de determinação variou de 0,9614 para a suspensão 1 a 0,9967 para a suspensão 8; estes valores por serem muito próximos de 1, representam uma correlação satisfatória dos dados experimentais com o modelo matemático proposto (modelo de Ostwald de Waale). Os fluidos pseudoplásticos seguem o modelo da potência, em que $\mathbf{n}$, neste modelo, assume valores menores que 1 e maiores que 0 . $O$ índice do comportamento de fluxo (n) variou de 0,3101 para a suspensão 1 a 0,5877 para a suspensão 6 . Esse índice indica o quanto o comportamento de fluxo do fluido se afasta do comportamento newtoniano; fluidos com valores próximos da unidade apresentam comportamento próximo de um fluido newtoniano. O índice de consistência do fluido (K) variou de 0,207 para a suspensão 6 a 1,2894 para a suspensão 10. Esse índice, por sua vez, indica o grau de resistência do fluido ao escoamento; quanto maior o valor de $\mathrm{K}$, maior a sua resistência ao escoamento e, portanto, maior a sua viscosidade. A suspensão argilosa 10 foi formulada com uma maior concentração de CMC2, o qual apresenta uma maior massa molar em relação ao $\mathrm{CMC1}$, justificando assim o maior valor do índice de consistência observado, consequentemente maior sua resistência ao escoamento.

$\mathrm{Na}$ Tabela III estão apresentados os resultados das propriedades reológicas (Viscosidade Aparente - VA, Viscosidade Plástica - VP, Limite de Escoamento - LE e Força Gel - FG) obtidas para as suspensões argilosas preparadas de acordo com a Tabela I.

Pode-se observar melhoria nas propriedades reológicas das suspensões aditivadas com $\mathrm{CMC1}$ ou 2, quando comparados a suspensão 1 preparada apenas com argila.

Tabela III - Propriedades reológicas das suspensões argilosas. [Table III - Rheological properties of the clay suspensions.]

\begin{tabular}{ccccc}
\hline Suspensões & VA $(\mathrm{cP})$ & $\mathrm{VP}(\mathrm{cP})$ & $\mathrm{LE}\left(\mathrm{N} / \mathrm{m}^{2}\right)$ & $\mathrm{FG}\left(\mathrm{N} / \mathrm{m}^{2}\right)$ \\
\hline 1 & 7,5 & 5,0 & 5,0 & 3,0 \\
2 & 11,0 & 7,0 & 8,0 & 2,0 \\
3 & 14,5 & 10,5 & 8,0 & 2,5 \\
4 & 17,0 & 13,0 & 8,0 & 2,0 \\
5 & 11,8 & 8,5 & 6,5 & 2,5 \\
6 & 13,5 & 10,0 & 7,0 & 2,0 \\
7 & 16,5 & 12,5 & 8,0 & 2,0 \\
8 & 24,3 & 15,5 & 17,5 & 14,5 \\
9 & 32,0 & 21,5 & 21,0 & 21,0 \\
10 & 41,8 & 28,5 & 26,5 & 29,5 \\
11 & 22,5 & 15,0 & 15,0 & 17,0 \\
12 & 30,8 & 20,5 & 20,5 & 22,0 \\
13 & 39,0 & 26,0 & 26,0 & 29,5 \\
\hline
\end{tabular}


Os melhores resultados foram obtidos para as suspensões preparadas com maior concentração de CMC2 $(2 \mathrm{~g} / 350 \mathrm{~mL}$ de água), como é o caso das suspensões 10 e 13, que apresentaram valores mais elevados para a viscosidade aparente, viscosidade plástica, limite de escoamento e força gel, sendo estes valores para VA de 41,8 e 39,0 cP; para VP de 28,5 e $26,0 \mathrm{cP}$; para LE de 26,5 e $26,0 \mathrm{~N} / \mathrm{m}^{2}$ e para FG de 29,5 e $29,5 \mathrm{~N} / \mathrm{m}^{2}$, respectivamente. $\mathrm{O}$ aumento da viscosidade das suspensões aditivadas com polímeros deve-se à dispersão e, consequente, hidratação das cadeias poliméricas pelas moléculas de água. Neste caso, o polímero possui maior volume hidrodinâmico em virtude da configuração alongada assumida após hidratação, implicando em maior viscosidade da solução $[25,26]$. A suspensão 1 desenvolveu um sistema disperso e defloculado (as partículas argilosas estão dispersas no meio líquido), traduzido pelos menores valores de VA, VP e LE, sendo estes valores de 7,5 $\mathrm{cP}$ para a VA, 5,0 cP para a VP e $5,0 \mathrm{~N} / \mathrm{m}^{2}$ para o LE. De acordo com caracterização física e mineralógica realizada em estudos anteriores [16, 27] da amostra de argila Volclay, sabe-se que esta argila é naturalmente sódica, apresenta elevada Capacidade de Troca de Cátions e área específica, alto teor de partículas coloidais e quantidade reduzida de minerais acessórios. Tais características aliadas ao baixo teor de argila utilizada contribuem para que as suspensões formuladas apresentem baixa viscosidade. A aditivação com calcita, embora tenha aumentado a concentração de sólidos nas suspensões argilosas, pouco afetou o desempenho reológico das mesmas; isto aconteceu provavelmente porque a calcita é um sólido inerte e pouco solúvel em água, a qual foi adicionada nas suspensões em estudo com o objetivo principal de reduzir as perdas por filtração [28].

As suspensões argilosas preparadas com $\mathrm{CMC1}$ e calcita (suspensões 5, 6 e 7) e, com CMC2 e calcita (suspensões 11,12 e 13) apresentaram estado disperso e floculado. Este estado provavelmente foi favorecido pela associação face-a-aresta das partículas de argila e pelo mecanismo de adsorção do polímero na argila. As suspensões preparadas com argila e CMC1 (suspensões 2, 3 e 4) e, as suspensões preparadas com argila, CMC 1 e calcita (suspensões 5, 6 e 7) apresentam redução nos valores das propriedades reológicas, comparados aos resultados obtidos para as suspensões preparadas com $\mathrm{CMC} 2$ (suspensão 8 à suspensão 13). Esse comportamento deve-se ao fato da CMC 1 ser um polímero de cadeia curta, que possui como principal função reduzir a taxa de filtração. Polímeros de cadeia curta agem geralmente como defloculantes, pois proporcionam neutralização de parte das cargas positivas das partículas de argila, uma a uma, recobrindo-as nas extremidades e aumentando a distância entre elas [29]. A adição da CMC2 conduziu as suspensões a um maior estado de floculação, caracterizado pelos elevados valores reológicos observados. Este comportamento sugere que a adição de polímero de maior massa molar e, portanto, cadeia mais longa, diminui a distância entre as partículas de argila através dos efeitos de encapsulamento e formação de pontes, favorecendo a floculação e não agindo como colóide protetor [10].
Através dos resultados apresentados acima, observase que quanto maior o grau médio de polimerização (DP) do aditivo polimérico, maior o estado de floculação das suspensões. Como a ação viscosificante da $\mathrm{CMC1}$ foi menos pronunciada em relação ao $\mathrm{CMC} 2$, sugere-se o uso deste aditivo em concentração superior a $2 \mathrm{~g} / 350 \mathrm{~mL}$, a fim de proporcionar ganho nas viscosidades das suspensões argilosas.

\section{Avaliação das propriedades de filtração}

Na Tabela IV encontram-se os resultados das propriedades de filtração (Volume de Filtrado - VF; Espessura de Reboco - h; Permeabilidade do Reboco - k e Poder de Retenção - R) obtidas para as suspensões argilosas preparadas de acordo com a Tabela I.

Tabela IV - Propriedades de filtração das suspensões argilosas.

[Table IV - Filtration properties of the clay suspensions.]

\begin{tabular}{ccccc}
\hline Suspensões & VF $(\mathrm{mL})$ & $\mathrm{h}(\mathrm{mm})$ & $\begin{array}{c}\mathrm{k} \\
\left(10^{-3} \mathrm{mD}\right)\end{array}$ & $\mathrm{R}$ \\
\hline 1 & 23,0 & 1,101 & 2,266 & 15,22 \\
2 & 12,0 & 0,906 & 0,973 & 29,17 \\
3 & 11,6 & 0,929 & 0,964 & 30,17 \\
4 & 10,7 & 1,094 & 1,048 & 32,71 \\
5 & 10,8 & 0,869 & 0,840 & 32,41 \\
6 & 9,3 & 0,920 & 0,766 & 37,63 \\
7 & 9,3 & 0,971 & 0,808 & 37,63 \\
8 & 10,6 & 1,827 & 1,733 & 33,02 \\
9 & 10,1 & 1,934 & 1,748 & 34,65 \\
10 & 9,7 & 2,126 & 1,846 & 36,08 \\
11 & 10,1 & 1,493 & 1,350 & 34,65 \\
12 & 9,5 & 1,798 & 1,529 & 36,84 \\
13 & 8,9 & 2,013 & 1,603 & 39,33 \\
\hline
\end{tabular}

A suspensão 1 apresentou maior valor de VF $(23,0 \mathrm{~mL})$, provavelmente devido a maior quantidade de água livre no sistema. Além disso, a composição desta suspensão não continha os controladores de filtrado carboximetilcelulose ou calcita. Comparando o valor do VF das suspensões que continham em sua composição argila e CMC1 (suspensões 2, 3 e 4) e, argila e CMC2 (suspensões 8, 9 e 10), respectivamente, com a suspensão 1 que continha em sua composição apenas argila, observou-se que os aditivos poliméricos atuaram de forma efetiva em sua função de reduzir as perdas por filtração. Esta redução foi mais pronunciada com a adição da máxima concentração de CMC2 estudada ( $2 \mathrm{~g} / 350 \mathrm{~mL}$ de água), onde o VF foi reduzido de 23,0 mL (suspensão 1) para 9,7 mL (suspensão 10). Este resultado era esperado, uma vez que, a CMC de maior massa molar em elevada concentração age aumentando a viscosidade e reduzindo o filtrado. Portanto, conforme resultados reológicos analisados anteriormente percebe-se 
que a suspensão 10 apresentou maior viscosidade em relação às demais suspensões argilosas estudadas, justificando assim o seu menor valor de VF. As suspensões argilosas aditivadas com polímeros tendem a apresentar melhor comportamento reológico e menor perda por filtração. Isto acontece, porque no meio aquoso, o polímero se expande devido à hidratação das cadeias poliméricas, diminuindo a água livre presente no sistema e como consequência tem-se o aumento da viscosidade e redução do VF. Esse fenômeno torna-se mais pronunciado quando da presença de argila bentonítica na suspensão. O polímero interage com a argila, devido à formação da camada de solvatação entre as cargas negativas do polímero e as cargas positivas presentes nas arestas das partículas de argila [25]. De acordo com a Tabela IV, pode-se observar também que as suspensões 7 e 13 apresentaram menores valores de VF, e, portanto melhores, sendo estes correspondentes aos valores de 9,3 e $8,9 \mathrm{~mL}$, respectivamente. $\mathrm{O}$ baixo valor de $\mathrm{VF}$ apresentado pela suspensão argilosa 7 era esperado, visto que esta suspensão foi preparada com concentração máxima de CMC1 (2 g/350 $\mathrm{mL}$ de água) e com calcita (selante), que tem como função reduzir as perdas por filtração. Percebe-se então, que a ação combinada entre as partículas de argila, polímero de cadeia curta $(\mathrm{CMC1})$ e calcita favorece a redução de perda da fase líquida da suspensão para as formações permeáveis, visto que a adsorção de polímero na superfície de partículas sólidas associada à viscosidade da suspensão argilosa influenciam os menores valores obtidos para o VF. Como o volume de filtrado também é influenciado pela viscosidade, maiores valores de viscosidades apresentados pela suspensão 13 conduziu a um menor valor de VF em relação às demais suspensões estudadas. A redução do volume de filtrado pela introdução de aditivos poliméricos em suspensões argilosas é explicada através dos mecanismos de estabilização eletrostática e de estabilização eletroestérica. A estabilização eletrostática ocorre como consequência da repulsão entre as cadeias do polímero ligadas às partículas de argila, enquanto que, a estabilização eletroestérica ocorre como consequência do aumento da distância mínima de separação entre as partículas de argila que estão envolvidas pelas cadeias poliméricas e pelas interações de caráter elétrico repulsivo entre as cadeias do polímero [19]. Estes mecanismos provavelmente favoreceram o menor estado de floculação apresentado pelas suspensões argilosas preparadas com CMC1 e calcita (suspensões 5, 6 e 7), obtendo-se um sistema disperso e floculado.

Uma vantagem da estabilização estérica sobre a estabilização eletroestérica é sua relativa insensibilidade à presença de eletrólitos, ou seja, a floculação das partículas de argila pela presença de eletrólitos pode ser evitada se estas estiverem envolvidas pelas cadeias do polímero [30].

De acordo com a literatura, polímeros de baixa massa molar adsorvidos às superfícies das partículas de argila e calcita promovem a maior dispersão destas partículas colaborando para a redução do filtrado. No entanto, alguns autores enfatizam que esta redução do volume de filtrado é alcançada principalmente pelos polímeros não adsorvidos às partículas coloidais que preenchem os poros do reboco, reduzindo as taxas de filtração [31]. Assim, analisando ainda os resultados de VF, foi possível verificar que o volume de filtrado foi reduzido com o aumento da concentração de aditivo polimérico nas suspensões (argila, $\mathrm{CMC1}$ e calcita; argila, $\mathrm{CMC} 2$ e calcita) em relação as suspensões (argila e $\mathrm{CMC} 1$ ou 2). A formação de reboco de pequena espessura e impermeável ao longo das paredes do poço é fator decisivo ao bom desempenho da suspensão. O reboco é constituído pelos sólidos gerados durante a perfuração e pelos sólidos existentes na própria suspensão e tem a finalidade de consolidar as paredes do poço, minimizar os riscos de desmoronamentos e reduzir a filtração frente às camadas que estão sendo perfuradas, evitando perda da fase contínua da suspensão através das formações rochosas permeáveis [32]. Para a espessura de reboco, verificou-se que as suspensões argilosas 2 e 5 apresentaram os menores valores de h, sendo estes valores de 0,906 e $0,869 \mathrm{~mm}$, respectivamente. Estas suspensões apresentam em sua composição o $\mathrm{CMC1}$, o qual em baixa concentração $(1 \mathrm{~g} / 350 \mathrm{~mL}$ de água) favoreceu a formação de um reboco com menor espessura. Podese observar também que as suspensões argilosas 10 e 13 apresentaram elevados valores de $\mathrm{h}$ quando comparados às demais, sendo estes valores de 2,126 e 2,013 mm, respectivamente. Com base na composição das suspensões 10 e 13 percebe-se que as mesmas foram preparadas com concentração máxima ( $2 \mathrm{~g} / 350 \mathrm{~mL}$ de água) de $\mathrm{CMC} 2$, e na composição da suspensão 13 foi acrescentado ainda a calcita. A CMC2 conferiu as suspensões maiores valores de viscosidades e a calcita de acordo com a sua análise granulométrica é constituída por partículas grosseiras, dessa forma as suspensões 10 e 13 apresentaram alto valor de $h$.

A permeabilidade do reboco é influenciada pela natureza das partículas coloidais existentes no sistema, tanto quanto pelo tamanho e forma. Dessa forma, os rebocos formados com suspensões de bentonita em água tem permeabilidades excepcionalmente baixas devido à forma planar das partículas, que facilita a deposição normal à direção do fluxo. Polímeros orgânicos, como os polieletrólitos (CMC), são adsorvidos nas partículas sólidas dispersas no fluido e obstruem parcialmente os poros do reboco [16]. As suspensões 6 e 7 que continham CMC1 e calcita em sua composição apresentaram valores de $\mathrm{k}$, sendo estes valores de 0,766 e $0,808 \times 10^{-3} \mathrm{mD}$, respectivamente, inferiores quando comparados as demais suspensões argilosas estudadas. Ainda de acordo com a Tabela IV, observou-se que as suspensões 1 e 10 apresentaram elevados valores de permeabilidade, sendo estes valores de 2,266 e $1,846 \times 10^{-3} \mathrm{mD}$, respectivamente, quando comparado com as demais suspensões argilosas. A elevada permeabilidade neste caso está relacionada com os altos valores de VF e h, uma vez que a permeabilidade do reboco é fortemente influenciada por essas duas propriedades de filtração. Quanto maior a permeabilidade adquirida pelo reboco menor será o controle de filtração. O poder de retenção é inversamente proporcional ao volume de filtrado, quanto menor o volume de filtrado, maior será o poder de retenção, ocasionando em menores 



Figura 3: Curvas de spurt loss para as suspensões preparadas apenas com argila (suspensão 1), com argila e CMC1 (suspensões 2, 3 e 4) e, com argila, CMC1 e calcita (suspensões 5, 6 e 7).

[Figure 3: Spurt loss curves for the suspensions prepared only with clay (suspension 1), with clay and CMC1 (suspensions 2, 3 and 4) and with clay, CMC1 and calcite (suspensions 5, 6 and 7).]

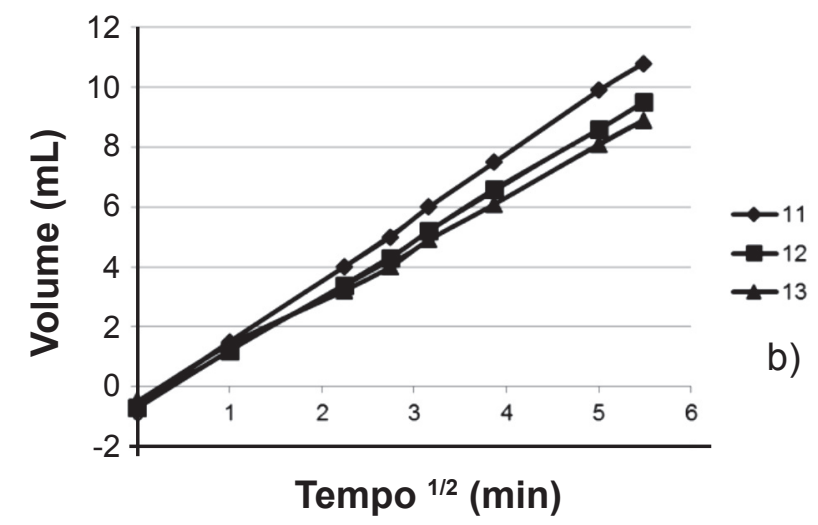

danos à formação rochosa. Portanto, as suspensões 7 e 13 apresentaram maiores valores de $\mathrm{R}$, sendo estes valores de 37,63 e 39,33, respectivamente. Conforme resultado elevado de $\mathrm{R}$, fica evidenciado que a presença da calcita associada à argila bentonítica nestas suspensões apresentam partículas menores que o diâmetro médio dos poros do meio filtrante, as quais formarão um reboco interno e externo de forma a possibilitar a invasão de filtrado para o interior da formação rochosa de forma controlada.

A partir dos valores encontrados para o volume de filtrado, em diferentes tempos, foram plotados os gráficos para determinar a perda de filtrado inicial, spurt loss. Os gráficos estão apresentados nas Figs. 3 e 4. E na Tabela V encontram-se as equações das curvas, os coeficientes de determinação e os valores do spurt loss para as suspensões argilosas estudadas.

O coeficiente de determinação de todas as suspensões argilosas estudadas foi da ordem de 0,99, valor muito próximo de 1 , o que representa uma ótima correlação dos dados experimentais com o modelo matemático proposto (Modelo Linear). O processo de filtração de um fluido contendo sólidos suspensos apresenta duas fases distintas. A primeira, denominada de filtração inicial, reúne dois estágios: o primeiro, conhecido por surge loss é definido pela invasão

Figura 4: Curvas de spurt loss para as suspensões preparadas apenas com argila (suspensão 1), com argila e CMC2 (suspensões 8, 9 e 10) e, com argila, CMC2 e calcita (suspensões 11, 12 e 13).

[Figure 4: Spurt loss curves for the clay suspensions prepared only with clay (suspension 1), with clay and CMC2 (suspensions 8, 9 and 10) and with clay, CMC2 and calcite (suspensions 11, 12 and 13).]

de partículas sólidas no meio poroso, com a formação de um reboco interno, sem, no entanto, ocorrer deposição de sólidos sobre a superfície porosa; o segundo, conhecido por transition loss se inicia com o depósito de partículas sólidas sobre a superfície porosa e se encerra no momento em que o reboco se torna uniforme, isto é, no momento em que a influência do depósito de partículas sobre o processo de filtração passa a ser negligenciável. A segunda e última fase de filtração, denominada de filtração propriamente dita, é reconhecida a partir do momento em que o volume acumulado de filtrado varia linearmente com a raiz quadrada do intervalo de tempo e o gradiente de pressão, através do reboco, se torna essencialmente constante [33]. Todos os valores encontrados para o spurt loss foram negativos, isto significa que os poros do papel de filtro fecharam quase que instantaneamente quando da aplicação da pressão. Diante disto, o segundo estágio da primeira fase, o transition loss, iniciou logo após a aplicação da pressão. Os valores negativos apresentados pelas suspensões argilosas estudadas são normais e representam o volume compreendido entre o papel de filtro e a válvula de escape do equipamento [34]. Valores negativos para o spurt loss, não têm significado físico e confirma o volume nulo de filtrado obtido experimentalmente no instante em que começou a filtração [35]. 
Tabela V - Equações, parâmetros e valores de spurt loss das suspensões argilosas.

[Table V - Equations, parameters and spurt loss values of the clay suspensions.]

\begin{tabular}{cccc}
\hline Suspensões & Equação & $\mathrm{R}^{2}$ & Spurt loss \\
\hline 1 & $\mathrm{y}=4,2515 \mathrm{x}-0,2521$ & 0,9999 & $-0,25$ \\
2 & $\mathrm{y}=2,4202 \mathrm{x}-1,2076$ & 0,9992 & $-1,21$ \\
3 & $\mathrm{y}=2,1392 \mathrm{x}-0,1924$ & 0,9998 & $-0,19$ \\
4 & $\mathrm{y}=1,9465 \mathrm{x}-0,0604$ & 0,9996 & $-0,06$ \\
5 & $\mathrm{y}=2,0988 \mathrm{x}-0,6576$ & 0,9998 & $-0,66$ \\
6 & $\mathrm{y}=1,7946 \mathrm{x}-0,6793$ & 0,9989 & $-0,68$ \\
7 & $\mathrm{y}=1,8411 \mathrm{x}-0,8923$ & 0,9993 & $-0,89$ \\
8 & $\mathrm{y}=2,0376 \mathrm{x}-0,5804$ & 0,9999 & $-0,58$ \\
9 & $\mathrm{y}=1,9483 \mathrm{x}-0,6383$ & 0,9939 & $-0,64$ \\
10 & $\mathrm{y}=0,8608 \mathrm{x}-0,4301$ & 0,9999 & $-0,43$ \\
11 & $\mathrm{y}=2,0988 \mathrm{x}-0,6576$ & 0,9998 & $-0,66$ \\
12 & $\mathrm{y}=1,8667 \mathrm{x}-0,7211$ & 0,9997 & $-0,72$ \\
13 & $\mathrm{y}=1,7067 \mathrm{x}-0,4988$ & 0,9987 & $-0,50$ \\
\hline
\end{tabular}

\section{CONCLUSÕES}

As suspensões argilosas estudadas apresentaram comportamento de fluido não newtoniano e pseudoplástico, uma vez que houve diminuição da viscosidade aparente em função do aumento da taxa de cisalhamento aplicada; mudanças nas propriedades reológicas foram observadas com a variação das concentrações de $\mathrm{CMC}$, sendo estas propriedades influenciadas diretamente pelo grau médio de polimerização dos aditivos poliméricos; as suspensões argilosas preparadas com elevada concentração de CMC2 (2 g/350 mL de água) apresentaram melhores valores de propriedades reológicas; a $\mathrm{CMC} 1$ tradicionalmente utilizada para redução do volume de filtrado, proporcionou uma redução semelhante a da CMC2, aditivo que também contribuiu para o aumento da viscosidade da suspensão argilosa, ao contrário da $\mathrm{CMC1}$, que é defloculante. Os menores valores de VF foram obtidos quando da aditivação com concentração máxima de $\mathrm{CMC} 1$ ou 2 (2 g/350 mL de água) e com calcita (10 g/350 mL de água); menores valores de espessura de reboco (h) foram obtidos com as suspensões argilosas preparadas com menor concentração de CMC1 ( $1 \mathrm{~g} / 350 \mathrm{~mL}$ de água); menores valores de permeabilidade podem ser obtidos quando da preparação da suspensão argilosa com maiores concentrações de $1(1,5$ e 2 g/350 mL de água) e com calcita; elevados valores de poder de retenção foram obtidos para as suspensões argilosas aditivadas com concentração máxima de CMC1 ou 2 (2 g/350 mL de água) e com calcita; todas as suspensões argilosas estudadas apresentaram valor de spurt loss negativo.

\section{AGRADECIMENTOS}

Ao CNPq pelo apoio financeiro, ao LABDES e ao PeFLab
(Laboratório de Pesquisa em Fluidos de Perfuração) pelo uso de suas instalações físicas e apoio à pesquisa, às empresas BUN (Bentonit União Nordeste Ltda.) e System Mud an Imdex Ltd. Co. pelo fornecimento das amostras de argila bentonítica e de calcita, respectivamente, e ao IBP (Instituto Brasileiro de Petróleo, Gás e Biocombustíveis) pelo suporte financeiro para a compra dos aditivos poliméricos.

\section{REFERÊNCIAS}

[1] R.B.Z.L. Moreno, J.E. Bonet, A.T.A. Waldmann, A.L. Martins, $4^{\circ}$ Cong. Bras. Pesq. Desenv. Petróleo e Gás, Campinas, SP (2007) 1.

[2] J.E. Thomas, Fundamentos de engenharia de petróleo, Ed. Interciência Ltda., Rio de Janeiro, RJ (2001) 271p.

[3] J.C.V. Machado, Reologia e escoamento de fluidos Ênfase na indústria do petróleo, Ed. Interciência Ltda., Rio de Janeiro, RJ (2002) 257p.

[4] R.R. Menezes, L.F.A. Campos, H.S. Ferreira, L.N. Marques, G.A. Neves, H.C. Ferreira, Cerâmica 55 (2009) 349.

[5] R.C.A.M. Nascimento, J. Magalhães, E. Pereira, L.V. Amorim, Rev. Matéria 18, 2 (2013) 1329.

[6] C.E.C. Souza, "Ensaios sobre os mecanismos de ação de aditivos poliméricos em fluidos de perfuração", Tese Dr. Quim. Org., UFRJ, RJ (2007) 231f.

[7] T. Hamida, E. Kuru, M. Pickard, J. Petroleum Sci. Eng. $72(2010) 33$.

[8] R.R. Menezes, L.N. Marques, L.A. Campos, H.S. Ferreira, L.N.L. Santana, G.A. Neves, Appl. Clay Sci. 49 (2010) 13.

[9] S.B. Hamed, M. Belhadri, J. Petroleum Sci. Eng. 67 (2009) 84.

[10] L.V. Amorim, "Melhoria, proteção e recuperação da reologia de fluidos hidroargilosos para uso na perfuração de poços de petróleo", Tese Dr. Eng. Proc., UFCG, PB (2003) $326 f$.

[11] A.M. Alsabagh, M.I. Abdou, A.A. Khalil, H.E. Ahmed, A. A. Aboulrous, Egyptian J. Petroleum 23 (2014) 27.

[12] J.C. Caraschi, S.P. Campana Filho, Polímeros Ciência e Tecnologia 9, 2 (1999) 70.

[13] Disponível em http://www.enartis.com.pt/download/ Cellogum.pdf, acesso em 16/02/2015.

[14] S. Bayarri, L. González-Tomás, E. Costell, Food Hydrocolloids 23 (2009) 441.

[15] K.V. Farias, "Influência de umectante aniônico na reologia e espessura do reboco de fluidos hidroargilosos", Diss. Mestrado Eng. Quim., UFCG, PB (2005) 68f.

[16] K.C. Nóbrega, "Efeitos da adição da CMC e da calcita nas propriedades de filtração de fluidos argilosos", Diss. Mestrado Ci. Eng. Mater., UFCG, PB (2015) 85f.

[17] M. Dolz, J. Jiménez, M.J. Hernández, J. Delegido, A. Casanovas, J. Petroleum Sci. Eng. 57 (2007) 294.

[18] L.D. Medeiros, J.C. Queiroz Neto, D.F.S. Petri, $10^{\circ}$ Cong. Bras. Polímeros, Foz do Iguaçu, PR (2009).

[19] V.C. Kelessidis, E. Poulakakis, V. Chatzistamou, Appl. Clay Sci. 54 (2011) 63. 
[20] M. Vikas, J. Rajat, Int. J. Res. Eng. Technol. 2 (2013) 150.

[21] K.R. Santana, "Interações entre a carboximetilcelulose, carbonato de cálcio e bentonita: repercussões sobre as propriedades dos fluidos de perfuração aquosos", Tese Dr. Ci. Amb. Tecnol., UFRN, Natal, RN (2014) 93f.

[22] PETROBRAS, "Viscosificante para fluidos usados na exploração e produção de poços de petróleo e gás”, EP-1EP00011-A (2011).

[23] ANSI/API 13I, Recommended practice for laboratory testing of drilling fluids, $8^{\text {th }} \mathrm{Ed}$. (2009).

[24] I.R. Oliveira, A.R. Studart, R.G. Pileggi, V.C. Pandolfelli, Dispersão e empacotamento de partículas Princípios e aplicações em processamento cerâmico, Ed. Fazendo Arte, S. Paulo, SP (2000) 224p.

[25] R.C.A.M. Nascimento, "Estudo do fenômeno de prisão diferencial e da estabilidade térmica de fluidos argilosos", Tese Dr. Ci. Eng. Materiais, UFCG, PB (2013) 138f.

[26] K.C. Melo, T.N.C. Dantas, E.L. Barros Neto, Holos 5 (2013) 3.

[27] T.T. Santos, "Estudo das propriedades de filtração de fluidos de perfuração aquosos", Diss. Mestrado Ci. Eng.
Materiais, UFCG, PB (2014) 76f.

[28] C. Rubim, Ano XIII Ed. 73, Rev. Portal Meio Filtrante (2015).

[29] M.I.R. Barbosa, L.V. Amorim, H.C. Ferreira, $4^{\circ}$ Cong. Bras. Pesq. Desenv. Petróleo e Gás, Campinas, SP (2007) 4. [30] P.F. Luckham, S. Rossi, Adv. Colloid and Interface Sci. 82 (1999) 43.

[31] C. Durand, J. Lecourtier, E. Rosenberg, L, Loeber, Rev. l'Institut Français du Pétrole 51 (1997) 777.

[32] A.S.F.S. Ferraz, "Efeito da distribuição granulométrica de partículas sólidas e de polímeros aniônicos na formação da torta de filtração e no volume de filtrado", Diss. Mestrado Ci. Eng. Quim., UFRRJ, RJ (2014) 108f.

[33] A.T. Bourgoyne Júnior, K.K. Millheim, M.E. Chenevert, F.S. Young Júnior, Applied Drilling Engineering, SPE Textbook Series, Texas, EUA (1986) 502p.

[34] R. Caenn, H.C.H. Darley, G.R. Gray, Composition and properties of drilling and completion fluids, Sixth Ed., Gulf Publ. Co., Houston, EUA (2011) 720p.

[35] D.A. Macedo, P.A.S. Araújo, B. Cela, M.R. Cesário, L.A. Nascimento, F.L.F. Andrade, $5^{\circ}$ Cong. Bras. Pesq. Desenv. Petróleo e Gás, Fortaleza, CE (2009) 5. (Rec. 18/02/2015, Rev. 10/06/2015, Ac. 22/06/2015) 